\title{
Chile entre pandemias: la influenza de 1918, globalización y la nueva medicina
}

\author{
Marcelo López y Miriam Beltrán
}

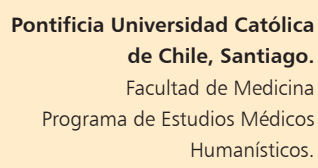

Pontificia Universidad Católica de Chile, Santiago.

Facultad de Medicina

Programa de Estudios Médicos Humanísticos.

Recibido: 28 de diciembre de 2012

Correspondencia a:

Marcelo López C. marclop@med.puc.c

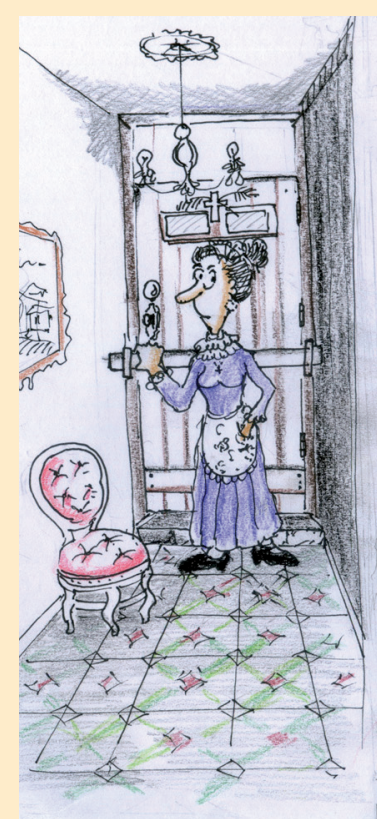

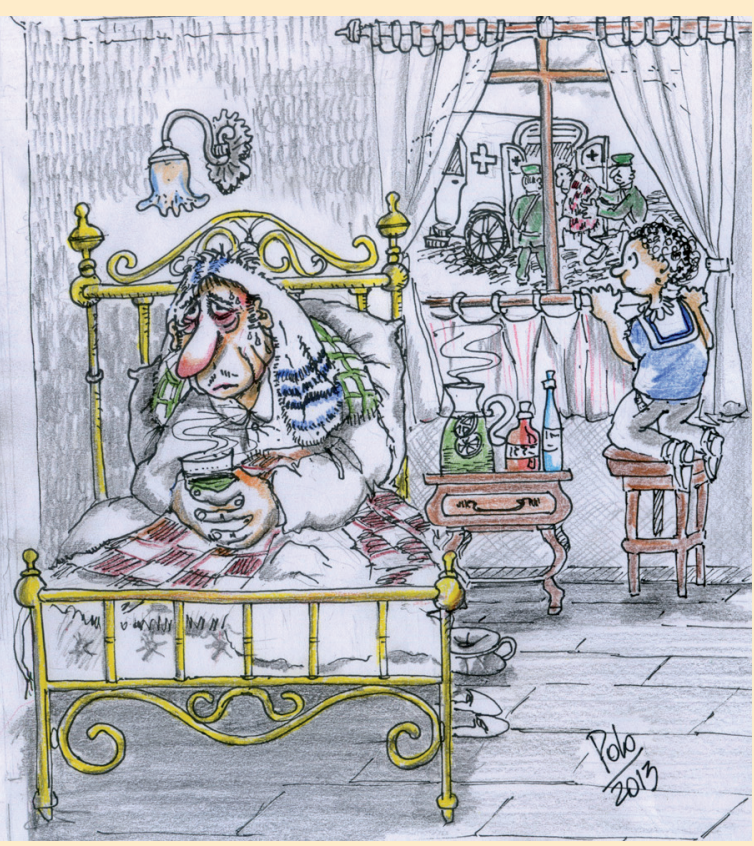

Presentación

U n episodio biológico se hizo presente en el otoño chileno del año 2009 el cual resultó ser inusitado para varias generaciones, pero al mismo tiempo fue familiar para otras que a mediados del siglo
XX ya habían conocido sus efectos. Nos referimos a la gripe porcina H1N1 fenómeno que asumió el carácter de influenza pandémica. Su impacto social produjo algunas particularidades que encajan con el contexto propio del sistema médico internacional que se gestó en el transcurso del siglo XX y que se ha caracterizado, en líneas generales, por la generación de respuestas de orden integral, en las que han convergido agentes políticos, científicos, económicos, entre otros. Sin embargo, desde un punto de vista histórico, la última pandemia nos permite asignarle un nuevo significado a aquello que el historiador francés Emmanuel Le Roy Ladurie denominó como "la unificación del mundo por la enfermedad", en virtud del cual la interrelación entre civilización moderna y naturaleza generó la creación de una suerte de "mercado común" de microorganismos. El último episodio de gripe porcina se inserta en ese linaje moderno de pandemias a las que la medicina científica pura y dura ha hecho frente desde el siglo XIX.

El presente estudio pretende abordar un evento pandémico en particular, precisamente el acaecido en el año 1918 en Chile. Si bien ese hecho forma parte del itinerario moderno de las pandemias de influenza, los historiadores coinciden en afirmar que a nivel global la gran pandemia de 1918 o popularmente conocida como influenza española ${ }^{1}$, ha sido uno de los más relevantes en la historia de la medicina moderna. Su importancia no solamente radica en las impactantes cifras de morta-

\footnotetext{
${ }^{1}$ No está demás mencionar que la pandemia de 1918 se originó en Estados Unidos, en Kansas y Texas según han sostenido la mayoría de los historiadores médicos que han estudiado el tema, y fue transportada a Europa por las tropas norteamericanas que participaron en la Primera Guerra Mundial. Actualmente, se discute la pertinencia de aplicar gentilicios a las epidemias puesto que ello puede prestarse para la generación de actitudes colectivas que se traducen en discriminación, proteccionismos y en la estigmatización de los países en donde se originan las pandemias.
} 
lidad y morbilidad que quedaron registradas en todos los continentes, sino que además en la enorme incertidumbre que generó en la comunidad médica científica que hacia el 1900 se había legitimado como uno de los motores del progreso social, gracias en parte a sus avances en la lucha contra epidemias históricas como la viruela, por ejemplo. Así, sobre ese contexto, pretendemos analizar las repercusiones de corto y mediano plazo que acarreó la pandemia de influenza para la sociedad chilena y al mundo de la salud y la enfermedad.

\section{Preámbulo histórico de la pandemia}

A comienzos del siglo XX, existía en Chile una serie de registros que avalaban la trayectoria histórica de la gripe. Uno que sin dudas merece ser citado es el del salubrista e historiador Pedro Lautaro Ferrer, quien la describió como una de las epidemias que regularmente asolaron al país en el período colonial, fenómeno que retrató citando el año 1737, hito que formó parte de la pandemia que se inició en Europa e ingresó a América por el virreinato de Nueva España. En ese año su presencia intimidó a la población y dio pábulo para "mil incidentes y supercherías"2. Estos hechos, sostuvo Ferrer, constituyeron un terreno fértil para los curanderos y hechiceros, y una demostración palpable del estado de inseguridad social que generan las epidemias. Hacia el siglo XIX una ola pandémica de influenza se desató entre 1889 y 1890 , proveniente desde la región central de Asia, específicamente en el territorio del Imperio ruso. A juicio del historiador J.N. Hays el carácter moderno de esta pandemia estuvo determinado por el papel que desempeñaron los medios de comunicación en la rápida difusión de la influenza hacia el Oeste, específicamente el ferrocarril y la navegación a vapor ${ }^{3}$. En efecto, en octubre de 1889 la influenza se hizo presente en San Petersburgo, y enero de 1890 se registraron los primeros casos en Buenos Aires, Ciudad del Cabo, Tokio, San Francisco, entre otras ciudades. Esa evidencia permite a varios historiadores suscribir a la perspectiva de análisis que entiende la globalización a partir de la difusión de las pandemias, como el caso de la influenza, aunque, naturalmente, no es el único caso histórico ilustrativo puesto que el cólera desempeñó un papel similar durante el siglo XIX. Más allá de las comparaciones que podamos establecer en este plano, lo cierto es que el impacto de la influenza hacia el 1900 fue un fenómeno registrado a nivel intercontinental.

\footnotetext{
${ }^{2}$ Ferrer, Pedro Lautaro. Historia general de la medicina en Chile. Desde el descubrimiento y conquista de Chile en 1535, hasta nuestros dias. Imprenta Talca, Talca, 1904, 259.

${ }^{3}$ Hays, J. N. Epidemics and pandemics. Their impacts in human history. ABC Clio, California, 2005, 315.
}

Junto a lo anterior, nos parece pertinente invocar otro factor que permite atribuir una estampa de modernidad a esa pandemia y que tiene relación con la capacidad de respuesta que demostró la comunidad médica internacional ante la presencia de la influenza. Esto por cuanto el evento biológico de 1889-1890 fue analizado por una medicina que contaba con bases científicas, y que en la práctica, por citar un ejemplo preclaro, recurrió a la emergente bacteriología para indagar sobre el microorganismo causante de la enfermedad. Es así que los trabajos del investigador alemán Richard Friedrich Pfeiffer encarnan no sólo una manera de conocer metódicamente la causa de la influenza, sino que una nueva mirada sobre el mundo inspirada en el poder de las ciencias decimonónicas.

Nuestro país no fue la excepción en ese escenario puesto que a comienzos de la década de 1890 alumnos de la Facultad de Medicina de la Universidad de Chile, examinaron la presencia de la enfermedad con ocasión de la ola pandémica que afectó a nuestro país, la cual para el joven facultativo José Luis Meléndez era “comparable con el exceso producido por el cólera asiático" 4 , y cuyas causas eran objeto de debate debido a que algunos médicos las atribuían a "variaciones ozométricas" y otros al "frío y la humedad." En la misma perspectiva científica, en 1893 Carlos Camus Luco subrayó en primer lugar un par de atributos distintivos de la enfermedad: primero, su velocidad de propagación, puesto que gozaba de "una extrema facilidad para propagarse de un punto a otro invadiendo, en pocos días, ciudades enteras $i$ aun continentes, distinguiéndose en esto del cólera i demás que necesitan de algún tiempo para generalizarse" ${ }^{\text {; }} \mathrm{y}$, segundo, su alcance universal puesto que millares de individuos eran atacados sin hacer distinción de sexo o condición social, cualidad que Meléndez también resaltó. Camus Luco observó además que pese a que se registraban casos en todas las estaciones del año, era el invierno la etapa predilecta para su propagación y aunque atacaba a todas las personas, su contagio se concentraba en los viejos y en los "individuos debilitados o valetudinarios." Un aspecto que el joven médico remarcó fue que la influenza era una enfermedad infecciosa, no obstante su "causa eficiente" no estaba plenamente determinada. La hipótesis que gozaba de un gran respaldo era la que atribuía la existencia de la enfermedad a un bacilo, como los trabajos de Pfeiffer en Berlín habían elucidado, afirmó el joven médico chileno. Respecto al bacilo, agregó que los investigadores " $l o$ habian visto en la sangre de los enfermos en el período

\footnotetext{
${ }^{4}$ Meléndez, José Luis. Influenza. Memoria para optar al título de licenciado en la Facultad de Medicina i Farmacia. 26 de abril de 1890, 2.

${ }^{5}$ Camus Luco, Carlos. La influenza o grippe. Memoria para optar al título de licenciado en la Facultad de Medicina i Farmacia. Septiembre de 1893, 2.
} 
febril i lo han visto desaparecer en la convalecencia". Si bien contribuían al desarrollo de la influenza la humedad, la temperatura y el resto de las condiciones atmosféricas, ellas tenían un carácter secundario ante la existencia del "germen causal."

Camus Luco prosiguió su examen afirmando que existían tres tipos de influenza, las que según su gravedad se clasificaban en tres formas, esto es, "abortiva", "ligera" y "grave", aunque recalcó que cualquiera que fuese el tipo de influenza que se detectara en todos ellos "era notable el gran cortejo de síntomas que la acompañaba" . Su curso era breve, entre tres a cuatro días al final del cual sobrevenía una crisis regularmente rápida, luego de la cual el enfermo entraba en convalecencia. En general la enfermedad se prolongaba por ocho a diez días, y algunas personas experimentaban debilidad por más tiempo del señalado. Los niños y ancianos eran más susceptibles a la enfermedad, y las mujeres morían en mayor proporción que los hombres. En términos generales, las personas que sufrían una enfermedad anterior como tuberculosis, bronquitis crónica, afecciones cardíacas, etc., alcanzaban una mayor mortalidad.

La presencia de la influenza en Chile en 1891 había revestido todas esas características, sembrando "la desolación i la muerte en casi toda la República". Si bien la mortalidad no había alcanzado un 5\%, la mayor parte de la población, entre un tercio y la mitad habían sido "víctima del azote," afirmó el facultativo, quien además, al comparar la última pandemia de cólera con la de influenza, no dudó en indicar que está última había causado más estragos. Un dato relevante que señala Camus Luco es que las personas más afectadas por influenza provenían de las "clases más acomodadas", hecho que reafirmaba el carácter universal de la enfermedad, y que establecía una diferencia respecto a las "enfermedades sociales" que, como la viruela, la tuberculosis, la sífilis, el cólera, la difteria, el tifus, etc., asolaban preferentemente a los sectores populares urbanos.

Otro aspecto destacado que cubre el estudio es el del tratamiento de la influenza, el cual combina procedimientos modernos y tradicionales, hecho que Camus Luco rubricó al advertir que no existía una terapia específica. Por lo tanto, por su calidad de mal infeccioso y contagioso, recomendaba una medicación "antiséptica i depurativa", aunque tal vez las manifestaciones ligeras de influenza podían ser susceptibles de ser atendidas con "bebidas calientes ligeramente alcoholizadas". También se sugería que los enfermos consumieran "caldos sustanciosos", leche y "vinos generosos", sobre todo en el período febril.

\footnotetext{
${ }^{6}$ Ibíd., 5.

${ }^{7}$ Ibíd., 8.

${ }^{8}$ Ibíd., 13

${ }^{9}$ Ibíd., 18.
}

Otros médicos recomendaban reposo en cama y "bebidas sudorificas $i$ excitantes". Para atacar el catarro bronquial apostaban por el consumo de una combinación de 20 gramos de jarabe de trementina más 8 gramos de jarabe tolú, de la cual se debía consumir 4 cucharadas al día ${ }^{10}$. Otras alternativas terapéuticas que se sugirieron de acuerdo a las diversas facetas que podían ofrecer la enfermedad, tales como la "gripe febril", la cual se atendía con quinina, o el "colapso en las pulmonías gripales", el cual debía ser tratado con cafeína en inyecciones hipodérmicas. Todo lo sostenido por Camus Luco adquiere aún más relevancia desde el momento en que detalla seis casos de personas afectadas por la influenza que lograron sanar en virtud de los tratamientos descrito por él en su memoria.

Los trabajos elaborados por los jóvenes médicos egresados, no solamente representan una lectura y respuesta moderna frente a los efectos de la influenza, sino que además pueden ser apreciados como manifestaciones de un momento de transición en la medicina chilena, dentro del cual se abandonaron teorías y prácticas imprecisas para acoger otras que añadieron mayor certeza. Es ese sentido, es factible hablar de un estado de maduración que la denominada "medicina científica" nacional alcanzó en el último decenio del siglo XIX, tras recorrer un camino que no estuvo libre de dificultades, tanto por el marco institucional dentro del cual se desenvolvió, como por las condiciones higiénicas, sociales y económicas del país las cuales en muchas ocasiones fueron un obstáculo insalvable para la acción sanitaria. La pandemia de influenza que sacudió al país en la década de 1890 y la respuesta que recibió por parte de la medicina local conformaron una experiencia histórica que nutrió el proceso de formación de las decenas de médicos que se educaron en la aulas de la Escuela de Medicina del Estado en las primeras décadas del 1900. Desde ese punto de vista, al despuntar el año 1918, el cuerpo médico nacional disponía de un punto de referencia concreto para encarar una epidemia de influenza a partir de cánones científicos que eran compartidos por gran parte de la comunidad científica internacional.

Como puede desprenderse de diversos estudios históricos, la influenza española se convirtió en un hito histórico no sólo por las vidas que cobró entre 1918 y 1920, cuyas cifras que oscilan entre 45 y 100 millones de personas, especialmente jóvenes ${ }^{11}$, sino que además porque su huella trastocó profundamente parte de los conocimientos adqui-

\footnotetext{
${ }^{10}$ Ibíd., 20.

${ }^{11}$ Los debates en torno a las cifras exactas sobre la mortalidad global ocasionada por la pandemia de influenza han sido una constante desde 1920 y no han existido acuerdos. Uno de los últimos estudios sobre el tema ha estimado que la mortalidad aproximada ronda en torno a los 50 millones. Johnson, N.; Mueller, J. Updating the accounts: Global mortality of the Spanish influenza pandemic. Bull History Med 2002; 76: 105-15.
} 
ridos por toda la medicina moderna que en el siglo XIX simbolizó científica y socialmente el ideal del progreso, cuyos avances fueron realmente efectivos en el combate de epidemias históricas. La pandemia de 1918 tiró por el suelo esa imagen épica, y contribuyó a incrementar la sensación de crisis que se instaló en el seno de muchas sociedades occidentales a partir de la Gran Guerra.

$\mathrm{Si}$ existe una forma de sopesar las consecuencias de la pandemia en nuestro país, los números reunidos por el Anuario Estadístico de la República de Chile respecto la mortalidad que produjo la gripe nos allanan el camino para elaborar un perfil de la huella que ella estampó en la sociedad chilena, y que estadísticamente se tradujo en 40.113 vidas en el período que comprenden los años 1918 y 1921, como se puede apreciar en la Figura 1.

A la impactante realidad que encerraron las cifras, debemos añadir el contingente de personal e instituciones médicas que existían en el país al momento del arribo de la pandemia, a efecto de entrever cuáles eran los recursos de que disponía la asistencia médica chilena cuando la población de Chile se aproximaba a los 4 millones de habitantes. ${ }^{12}$ La Tabla 1 nos ilustra al respecto

Todo este escenario sobre el que podemos explicar el estado de desarrollo en el que se situó la medicina chilena frente a la influenza española, no puede ser analizado cabalmente sin conectarlo con un proceso de mayor magnitud y cuya gestación se inició en el último tercio del siglo XIX. Nos referimos a la conformación de aquello que algunos historiadores han calificado con el surgimiento de una nueva conciencia sanitaria en el país que respondió a los cuestionamientos y discusiones que emanaron del fenómeno conocido como cuestión social. Para nuestro estudio, dicha mención importa en tanto los poderes públicos, a partir de ese período, paulatinamente comenzaron a articular una nueva institucionalidad en materia de salud pública que, pese a todas sus limitaciones, materializó una mayor participación del Estado chileno ante el desafío de la cuestión social sanitaria. La influenza de 1918, como tendremos la oportunidad de analizar a continuación, asoma como un escenario privilegiado para examinar ese proceso, específicamente, en la serie de discusiones a que dio pábulo la búsqueda de soluciones efectivas contra la pandemia. En esa tarea los médicos, la prensa y la sociedad presenciaron cómo la aplicación del primer Código Sanitario, la responsabilidad que le correspondía al Estado en el tratamiento de la influenza o la apuesta por una medicina más preventiva que curativa fueron temas que se instalaron como trasfondo de la contingencia que personificó la gripe.

\footnotetext{
${ }^{12}$ De acuerdo con el censo de población de 1920, vivían en el país 3.753.799 personas.
}

\section{La cultura médica chilena y la influenza}

Hace casi una década el historiador de la medicina Enrique Laval Román elaboró un estudio sobre la influenza de 1918 en el que quedó de manifiesto la inquietud en un primer momento produjo una particular situación epidémica: la convergencia de la gripe y el tifus exantemático. Las diferencias existentes entre las opiniones que se apoyaban en la clínica y las que se respaldaban en el laboratorio al momento de determinar en qué casos era posible hablar de influenza española y en cuáles de tifus exantemático, y la resolución final de la cuestión, son claramente examinadas en el trabajo citado y, por tal razón, no profundizaremos en ese terreno ${ }^{13}$.

${ }^{13}$ Laval R., Enrique. Chile 1918: las dos epidemias. Rev Chilena Infectol 2003; 20: 133-135.

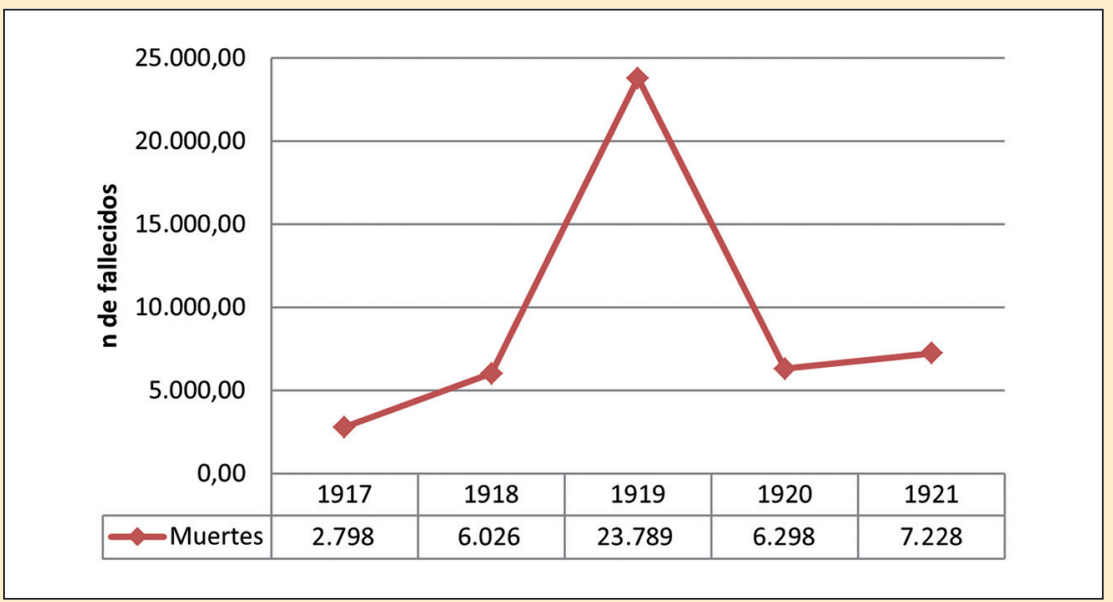

Figura 1. Muertes por influenza española en Chile, 1917-1921 (Anuario Estadístico de la República de Chile, años 1918, 1919, 1920 y 1921. Es importante hacer presente que del total de muertes contabilizadas entre 1918 y 1921, solamente 2.676 fueron certificadas por médicos, mientras que el resto de ellas, 37.437, fueron registradas por "testigos." Bajo esta figura se comprendía desde practicantes hasta funcionarios públicos ligados a los hospitales o el Registro Civil, hecho que nos introduce en uno de los debates que arrastró por décadas la salubridad moderna y que se refiere a la fiabilidad de las estadísticas médicas. Por ello, es pertinente valorar con cierta reserva la cifra que 40.113 muertos).

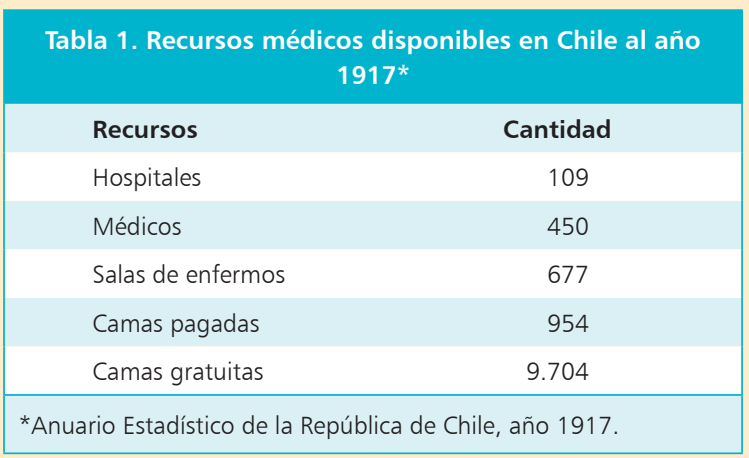


Nuestra propuesta pretende complementar ese estudio haciendo hincapié en otras áreas del escenario pandémico generado por la influenza, y así ofrecer nuevas perspectivas respecto a la relación que es posible tejer entre la sociedad chilena y un evento globalizador de la magnitud que representó la gripe de 1918. En virtud de ello, hemos querido abordar cómo la enfermedad en cuestión afectó la cultura médica de nuestro país, concepto bajo el cual incluimos las prácticas médicas a las que la población atendió para hacer frente a un mal que para muchos chilenos y chilenas fue tan mortífero como desconocido y sus efectos en la convivencia social.

El "garrotazo", el "mal de Santa María" o simplemente "gripe", como comúnmente era conocida la influenza en Chile, comenzó a cobra fuerza en la primavera de 1918 en la zona central del país, y, especialmente, en Santiago, ciudad a la que la enfermedad llegó proveniente desde Argentina y Valparaíso, según aventuró la prensa. Quienes eran afectados por la pandemia eran reconocidos por "andar con el cuerpo cortado", una señal ineludible de que a la víctima la influenza "la habia pescado en sus garras", como consignó la revista Sucesos a fines de octubre $^{14}$. Inicialmente, los lugares más afectados fueron aquellos que circundaban la zona en la que, como señaló la prensa, se detectaron los primeros casos, esto es, los barrios del mercado o Vega Central y el "Ultramapocho." El inspector sanitario, Manuel Camilo Vial, en una descripción que resume en sus líneas fundamentales el marco social que propició la expansión de la enfermedad, afirmó que, pese a los avances registrados en la construcción de obras sanitarias desde fines del siglo XIX, las lastimosas condiciones higiénicas, un problema cuya irresolución se había arrastrado por décadas en el Chile moderno, eran el caldo de cultivo para desarrollo de la enfermedad, particularmente, entre los sectores más vulnerables socioeconómicamente, condición que fue uno de los núcleos de la cuestión social sanitaria. No obstante, ello no impidió que las "clases acomodadas" no hubiesen padecido las consecuencias de la gripe, enfatizó el doctor Vial ${ }^{15}$.

La irrupción de la influenza y las permanentes informaciones que la prensa difundía respecto a su expansión a través de las ciudades, sumada a las acciones, exitosas o no, que emprendieron las autoridades médicas y municipales para enfrentarla, contribuyeron a materializar uno de los rasgos distintivos que ha sido posible percibir históricamente frente a este tipo de episodios: la incertidumbre social frente a un evento biológico de magnitud hasta entonces desconocida. Si bien nuestro país poseía una memoria médica respecto a las epidemias que por siglos habían afectados la vida de generaciones de chilenos y chilenas, la gripe española se convirtió en la

\footnotetext{
${ }^{14}$ Sucesos, 31 de octubre, 4 .

${ }^{15}$ El Mercurio, 20 de octubre, 17.
}

coyuntura apropiada para que en 1918 los habitantes de los principales centros urbanos recurrieran a las prácticas y saberes que integraban la cultura médica nacional. En otras palabras, las dudas y expectativas que infiltraron gran parte del diario vivir de la sociedad chilena en la primavera de aquel año, dieron vida a cierto grado de desconfianza generalizada hacia el otro, hacia el cuerpo médico e incluso, hacia los políticos.

Una primera tarea que se asumió colectivamente fue recurrir a una de las herramientas más utilizadas por la medicina moderna para luchar contra las epidemias sociales: la educación higiénica. Los periódicos nacionales fueron activos colaboradores en esta tarea cuya efectividad no dependía tanto de los médicos, sino que de la fe que cada habitante depositara en esos consejos. El diario porteño La Unión, por citar un ejemplo, publicó en el mes de octubre una serie de "reglas que la ciencia recomendaba" para hacer frente a la influenza entre las que destacaban: una alimentación sana en todo sentido; velar por el aparato respiratorio evitando "atmósferas confinadas" como cafés, tabernas y todo espectáculo público; cultivar la oxigenación, valiéndose de paseos al aire libre; y la limpieza de las ropas y utensilios que estuvieran expuestos al contacto con los enfermos ${ }^{16}$. Dichas campañas, si bien eran plausibles para algunos sectores de la sociedad, merecieron reparos desde la comunidad médica que acusó un hecho inevitable, esto es, la falta de precauciones adoptadas ante un hecho que era previsto, eso al menos se puede desprender de las afirmaciones sostenidas por La Tribuna Médica casi un año después de la irrupción de la influenza en Chile. En el fondo, la perspectiva que encerraba esa crítica apuntaba a la carencia de un sistema que inculcara entre el pueblo "mejores hábitos de aseo y limpieza"17, un antecedente de un nuevo modelo de medicina orientada hacia la prevención, que hacia la década de 1920 comenzó a institucionalizarse en la salubridad nacional.

Las acciones directas contra la gripe española, al igual que otras enfermedades infecciosas conocidas por la población y las autoridades, contemplaron la higienización de espacios públicos y privados que en gran medida alteraban la vida social de la comunidad y, como tal, podían ser objeto de rechazo. De este modo, por ejemplo, las inspecciones profilácticas se concentraron en los conventillos, verdaderos "paraísos de microbios", así como en establos, caballerizas, colegios, iglesias, hoteles, mercados, teatros, cárceles, transporte público, entre otros lugares propicios para las aglomeraciones, hecho que demostraba que la idea de contagio era una verdad universalmente aceptada. Ahora bien, todo ello podría ser considerado un procedimiento sanitario comprensible para

\footnotetext{
${ }^{16}$ La Unión, 19 de octubre, 6.

${ }^{17}$ La Tribuna Médica, septiembre de 1919, nº 226, 1.
} 
los responsables de la salud pública, aunque no necesariamente comprendido y aceptado por la población, por cuanto algunas autoridades, como el alcalde de Santiago, Rogelio Ugarte, amparándose en normas que contemplaba el Código Sanitario, que entraba en vigencia en enero de 1919, planteó en octubre de 1918 aislar a los "enfermos preliminares" en las denominadas Casas de Aislamiento, mientras el personal del Desinfectorio Público procedía a higienizar el hogar del contagiado. Naturalmente, en muchos casos, las relaciones familiares se perturbaban y, en consecuencia, no era extraño que las personas optaran por no denunciar los casos de influenza, hecho que es posible si atendemos a las palabras del Jefe de la Inspección Municipal de Santiago, José Luis Meléndez, quien tras visitar los sectores de Cumming, Mapocho, Avenida La Paz, Chacabuco a fines de octubre de 1918, reconoció que "hay una tendencia entre la gente pobre a ocultar a sus enfermos por temor a la hospitalización" ${ }^{18}$. Desde este punto de vista, se aprecia que la modernidad científica, a comienzos del siglo XX, se veía obstaculizaba con el tradicional recelo que los establecimientos hospitalarios despertaban en un sector de la ciudadanía, esta vez en un contexto pandémico.

Ante el despliegue de acciones de higienización que trastocaban la vida habitual de la ciudad, y el activo despliegue publicitario de normas higiénicas que incluso proponían restringir ritos sociales como el saludo de mano y la conversación a corta distancia, o actos de la vida íntima como besarse, la población dispuso de una serie de recursos terapéuticos, modernos o tradicionales, cuyo uso era proporcional a la confianza que se depositara en ellos. Desde la comunidad médica, personalidades como José Ducci recomendó la aplicación de la quinina, Juan de la Vega propuso el uso de pulverizaciones en la nariz, aceite mentolado, aspirina, y Tomás Quevedo sugirió inhalaciones de aceite mentolado ${ }^{19}$. En este mismo sentido, la actividad de las boticas en época de gripe, y que fue pesquisada por la prensa, puede ser considerada como un indicador de las decisiones adoptadas por las personas para hallar una pronta respuesta terapéutica (Figura 2). Así, de acuerdo con lo informado por el diario La Nación, algunos establecimientos del centro de Santiago reportaron un rápido aumento en la venta de preparaciones antisépticas, como el alcanfor, naftalina, sulfato de cobre, entre otras, al punto que muchas de ellas escasearon. Un hecho interesante que además es posible percibir en el mundo de los boticarios tiene relación con los motivos que llevaron a los afectados por la gripe a concurrir a esos locales, en particular, la imposibilidad de muchos de ellos de poder consultar a un médico por razones económicas, situación que no dejaba otra alternativa que

\footnotetext{
$\overline{{ }^{18} \text { El Diario Ilustrado, } 25}$ de octubre, 1918, 15.

${ }^{19}$ Sucesos, 31 de octubre, 7.
}

la venta de aspirinas o un desinfectante. En virtud de ese tipo de situaciones, desde cierta prensa crítica se acusó el actuar de los afirmar que frente a la pandemia reinante "los médicos ha perdido la cabeza, pero no el bolsillo" 20 .

Los boticarios instalados en la Avenida Independencia, entregaron otras aristas sobre las reacciones de los habitantes ante la influenza, dentro de las cuales asoma la masiva utilización de "medicinas caseras" para la transpiración, como el tilo, borraja, y otros tipos de diuréticos. Finalmente, un testimonio entregado por el dueño de una botica de ese barrio es bastante revelador de una conducta colectiva que estuvo estrechamente conectada con la desconfianza que sembró la enfermedad, y que en concreto tuvo que ver con el ocultamiento de los enfermos que realizaban las personas ante la posibilidad de que se efectuaran las inspecciones sanitarias, decisión que nos parece podía estar motivada tal vez por el temor

$\overline{{ }^{20} \text { Sucesos, } 24 \text { de octubre, }} 5$.
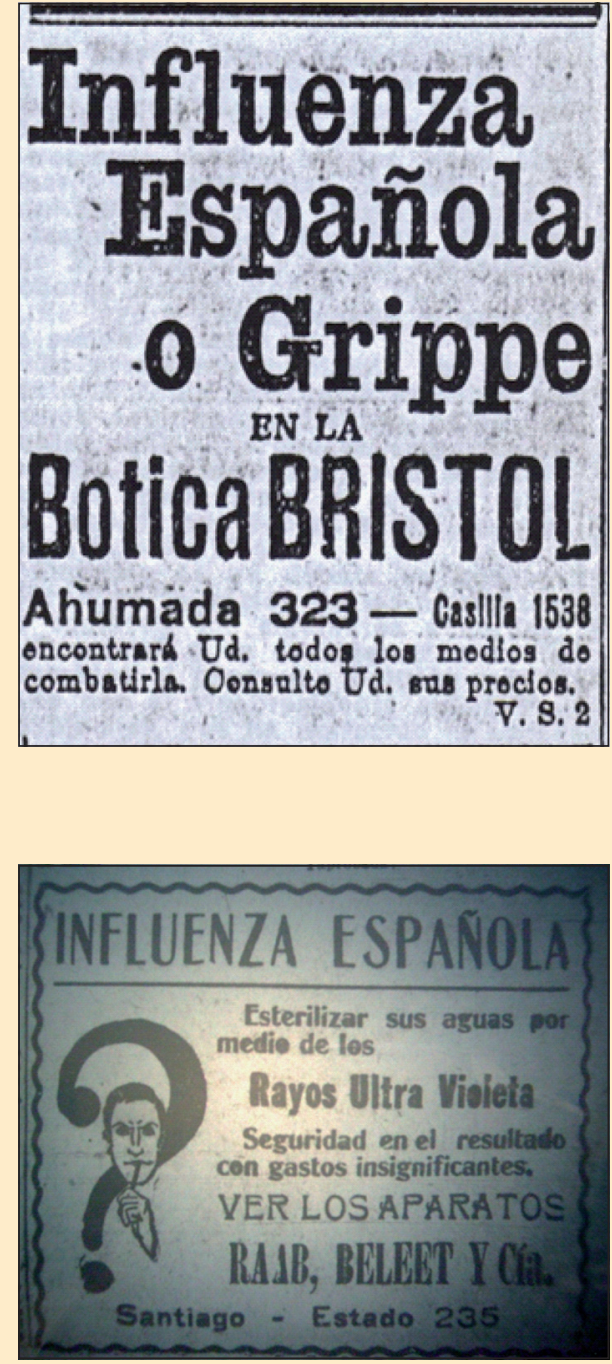

Figura 2. Publicidad farmacéutica. Fuente: El Diario llustrado.
Figura 3. Difusión de tecnología médica moderna contra la influenza. Fuente: $E$ I Mercurio. 
a la hospitalización, quizás por la suspicacia ante los tratamientos o bien por el deseo de mantener el vínculo con el núcleo familiar. De hecho, Carlos Martiz, dueño de una botica del sector de Independencia, indicó que las personas iban de noche a comprar los medicamentos y que, a su juicio, el barrio concentraba a 6.000 enfermos por influenza ${ }^{21}$. Certero o no su cálculo, lo cierto era que existió un importante grupo de santiaguinos que hicieron esfuerzos por mantenerse fuera del alcance de la campaña médica contra la enfermedad (Figura 3).

En suma, el panorama social que hemos descrito nos revela algunas características sobresalientes del impacto ocasionado por la influenza española y las vivencias experimentadas por la ciudadanía ante una circunstancia, que si bien tuvo ribetes de desgracia, paralelamente fue complementada con la certeza de que el país la superaría como lo habían hecho anteriores generaciones frente a fenómenos similares, aunque con un costo mayor para el trienio 1918-1920. Desde nuestra perspectiva es posible considerar que, más allá de la coyuntura que representó la influenza, ese episodio emergió como una oportunidad para que una elite médica ligada al mundo de la salubridad hiciera presente una vez más una suerte de desiderátum sanitario que se había gestado desde fines del siglo XIX y estaba condensado en un propósito: la solución a la cuestión social sanitaria dependía de la instauración de una salud pública moderna y de un papel activo del Estado en ese campo. Ciertamente, los adherentes a ese manifiesto habían conseguido algunos éxitos quizás más simbólicos que efectivos, como la fundación del Instituto de Higiene y del Consejo Superior de Higiene Pública, en la década de 1890, y la dictación del primer Código Sanitario en 1918. No obstante aquello, la gripe española dejo al desnudo que el nexo entre política y sanidad aún contenía vacíos, todo lo cual mermaba la eficacia de la acción médica a nivel nacional.

\section{La influenza y los poderes públicos}

No es difícil imaginar que a pesar de todos los intentos del mundo médico por frenar la epidemia, la gripe resultó ser el panorama habitual de las calles de Santiago y de las principales regiones del país. La prensa de modo constante, y en especial el diario La Nación, describieron a lo largo de sus páginas, cómo la Policía de Aseo y Ornato recorrió cada barrio capitalino inspeccionando y, eventualmente, clausurando conventillos, ferias y todos los lugares en donde se detectara algún atisbo de la enfermedad.

Finalmente el gobierno decidió actuar como respuesta a las críticas provenientes tanto de algunos sectores de la sociedad como del mundo médico, voces que encarnaban un malestar colectivo de lo que se estimaba como la

${ }^{21}$ La Nación, 27 de octubre, 16. inacción de los poderes públicos ante la gripe española. Una primera medida concreta que se pude calificar como importante fue la solicitud por parte del Ministro del Interior, Pedro García de la Huerta, de doscientos cincuenta mil pesos al Congreso para la habilitación de camas y para la compra de diversos materiales para la desinfección, aunque muchos de los cabecillas municipales se quejaron de la falta de recursos para afrontar los cada vez mayores focos de infección. En el campo de las soluciones específicas que se propusieron se indicó la necesidad de: organizar un servicio extraordinario de inspección, aislamiento y vigilancia médica, de acuerdo con las disposiciones del Código Sanitario; adoptar de acuerdo con la Junta de Beneficencia de Santiago las medidas que fueran convenientes para la hospitalización y aislamiento de los enfermos; $y$, una decisión fundamental para la comunidad médica, eso es, solicitar al Presidente de la República la inclusión de la enfermedad epidémica entra las que debe ser declarada por lo médicos, para que la profilaxis pueda hacerse en momento oportuno.

Pese a esos antecedentes, las respuestas de la autoridad ante la gripe, la mayor parte de ellas circunscritas al higienismo decimonónico, fueron recibidas por algunos sectores como superficiales en tanto no atacaron el problema central. Un claro ejemplo de ello lo constituyó la nueva función que se le otorgó a la policía de aseo de la ciudad: el lavado diario de las cunetas de las calles para impedir que se produzcan en ellas fermentaciones a causa de la aglomeración de desperdicios. Una similar solución fue solicitada por el alcalde de Santiago a la Inspección de Higiene para el caso de los teatros y biógrafos y otros lugares de afluencia masiva de público como el caso de los colegios para los cuales se dispuso de una serie de indicaciones para evitar la propagación de la epidemia, que no solamente apuntaron a los aspectos estrictamente higiénicos, sino que a las costumbres de los niños, para lo cual se recomendó la distribución de jabones y escupitines en los establecimientos escolares.

Si las medidas antes mencionadas resultaron ser de una cuestionable efectividad para muchos, la imagen de incapacidad de la acción de la autoridad sanitaria se acentuó entre la población a medida que el número de enfermos que día a día incrementaba las interminables esperas por atención en los hospitales de la ciudad. Sobre ese escenario no resulta extraño comprobar comprobar que surgiese dentro de la comunidad un ánimo de reproche hacia los encargados de la salubridad pública, sobre todo en momentos en que se adoptaron determinaciones polémicas, tales como la suspensión de la romería a los cementerios el $1^{\circ}$ de noviembre y la prohibición de la comercialización de en la Vega Central, lugar que parte de la prensa y del público identificó como el foco principal de contagio. Este episodio, además, nos permite plantearnos otra cuestión de fondo y que podemos describir como 
la tensión existente entre sociedad y autoridad, como lo ilustró El Diario Ilustrado al afirmar que la oposición de esos grupos de afectados respondió al conjunto de "intereses creados" 22 que se convertían en un obstáculo para las acciones sanitarias emprendidas por las instituciones públicas. Igualmente, dicha circunstancia dejó al descubierto cómo la economía urbana se engarzó de forma conflictiva con la salubridad por cuanto el sistema de venta de verduras de la ciudad fue señalado como un factor que propició el crecimiento de la influenza en vista a la concentración del expendio de hortalizas en un solo lugar, La Vega, situación que pudo evitarse si cada uno de los barrios santiaguinos hubiese contado con su propio mercado de hortalizas.

La proporción que alcanzó este conjunto de problemas, inexorablemente motivó que se elevaran voces que, a partir de una conciencia de la trayectoria modernizante que la sanidad en Chile había ido adquiriendo desde fines del siglo XIX, apuntaron sus cuestionamientos al sistema de asistencia médica imperante el cual, como sabemos, se sostenía sobre la base institucional que representaban la Beneficencia Pública, los consejos de higiene provinciales y los municipios. De ahí que resultara lógico que se expusieran cuestionamientos a la estructura sanitaria reinante y en particular al gobierno de Juan Luis Sanfuentes que estaba encargado de poner en vigencia uno de los frutos de la modernización de la organización de la salubridad chilena, el código sanitario. Este instrumento tuvo como propósito reformular el sistema sanitario chileno para lo cual se estableció una única entidad ejecutiva, la Dirección General de Sanidad, asistida por la creación de organismos sanitarios provinciales, es decir, un nuevo orden que ponía término a un viejo problema denunciado por el mundo de los salubristas nacionales y que consistió en la disgregación de la labor sanitaria en una serie de reparticiones públicas.

En particular, el tenor de las críticas estuvo dirigido a la escasa capacidad ejecutiva del Estado chileno el que, a pesar de haber anunciado públicamente la promulgación del nuevo código, y cuya vigencia plena se haría efectiva el $1^{\circ}$ de enero de 1919 , no fue competente para proponer soluciones adecuadas a partir del uso de herramientas que no requerían necesariamente de la nueva ley sanitaria. ${ }^{23}$ De este modo, y a pesar de las medidas higiénicas y profilácticas adoptadas tanto por el cuerpo médico, como

\footnotetext{
${ }^{22}$ El Diario Ilustrado, 28 de octubre, 3.

${ }^{23}$ Es importante agregar que gran parte de las disposiciones del código sanitario fueron objeto de discusión en el Congreso por muchos años en razón de que, para algunos sectores políticos representados por el partido Conservador, su aplicación afectaba intereses individuales, como la privacidad y el derecho de propiedad, principios que contrariaban los argumentos de quienes eran partidarios de la primacía del bien común y de la activa participación del Estado.
}

por los municipios, se hizo evidente para muchos que la pandemia era imposible de contrarrestar, puesto que con el transcurrir de los días se presentaban más casos, el mal se expandía a liceos, comisarias, bibliotecas etc., pero también a otras provincias, muchas de las que no dispusieron de los recursos para combatir dicho mal. A juicio de quienes fustigaban a los poderes públicos, el delicado escenario sanitario crítico por el que atravesaba gran parte del país, tenía su origen en la responsabilidad del Estado en tanto no había sido capaz de acoger y contener a la población enferma. Incluso se alegó que la epidemia puso de manifiesto la necesidad de que el orden de los servicios sanitarios debía contemplar que el trabajo de asistencia de los hospitales fuese complementado por el Instituto de Higiene ${ }^{24}$.

Desde la esfera médica también se insistió en el manejo comunicacional adoptado tanto por el gobierno de Sanfuentes como por algunos medios de prensa, como por ejemplo El Mercurio, quienes intentaron bajar el perfil del impacto de la influenza manifestando argumentos a la población que a los ojos de los salubristas eran poco fiables, a saber, que la gripe estaba controlada, que solamente afectaba a los sectores socio-económicamente precarios o que sus efectos realmente no eran tan graves. Los facultativos preocupados por los avances de la influenza y de la respuesta de las autoridades fueron enfáticos en declarar en noviembre de 1918 que "el diagnostico de la influenza debe también alejarse puesto que se sabe que esta enfermedad es esencialmente difusible, que ataca a un mismo tiempo a gran número de personas y a todas las clases sociales; chicos y grandes, débiles y robustos, todos enferman en breve tiempo." 25

Esta coyuntura hizo patente otro tema que para los médicos había sido objeto de cuestionamientos hacia los poderes público desde fines del siglo XIX: la declaración obligatoria de enfermedades contagiosas. Esa norma era apoyada por los salubristas básicamente porque permitía que la operación sanitaria fuese fructífera en la medida que se identificara prontamente a un enfermo y se movilizaran los recursos sanitarios correspondientes. Inexplicablemente para muchos médicos, al igual que había ocurrido en su momento con enfermedades sociales de primera magnitud en el Chile moderno como la tuberculosis y la sífilis, la influenza, en el año 1918, no integraba las el grupo de males infecciosos que podían ser objeto de declaración obligatoria, hecho que empeoraba la salud de la población debido a que por la rapidez con que se difundía la gripe española se hacía hace "imposible adoptar medidas de aislamiento o de desinfección oportunas." 26

Una interesante observación que podemos rescatar de los cuestionamientos planteados por los médicos

\footnotetext{
${ }^{24}$ La Tribuna Médica, $1^{\circ}$ de noviembre de 1918; 216: 1098.

${ }^{25}$ La Tribuna Médica, $1^{\mathrm{o}}$ de noviembre de 1918; $216: 1101$.

${ }^{26} \mathrm{La}$ Tribuna Médica, $1^{\text {o }}$ de noviembre de 1918; 216: 1102.
} 
tiene relación con las consecuencias a mediano plano que acarrearía la influenza en la etapa de post-pandemia. A juicio de los facultativos la negligencia demostrada por el Estado en el modo de enfrentar las epidemias infecciosas, y en particular en el caso de la gripe, ocasionaría que en los próximos años la salud pública chilena debería hacer cargo del incremento de "las enfermedades latentes en los organismos y la agravación de las afecciones"27, sobre todo la tuberculosis, todo lo cual se transformaría en una situación que a la luz de la cuestionable experiencia del sistema asistencial vigente, provocaría complejos estragos.

Hacia el últimos trimestre de 1918 el arribo de la influenza generó una serie de reacciones y debates en la sociedad que hemos delineado a partir de las opiniones y testimonios vertidas por los principales actores de ese pasaje inolvidable de la historia sanitaria chilena. Dentro del cúmulo de interrogantes que la mortal presencia de la ocasionó en el país, tal vez uno de los planteamientos hechos por el cuerpo médico respecto a las causas de la difusión de la enfermedad sea pertinente citar por su valor histórico. Ante la preocupante evolución que la epidemia fue tomando, no sólo en las provincias donde se inició la infección, sino que también en Santiago, y dado que se había comprobado una vez más que la improvisación y la "incuria" de las autoridades contribuyeron a que la afección tuviera una rápida difusión, más allá de las condiciones precarias en materia de higiene en las que vivía gran parte de la población más afectada, el proletariado urbano, es factible preguntarse si la influenza española fue el último gran episodio infeccioso que alentó la decisión de adoptar políticamente el modelo de la nueva medicina o medicina preventiva que cobró fuerza en la década de 1920 y que fue el núcleo de las políticas de salud que fructificaron en el país a lo largo del siglo XX. Quizás esa respuesta merezca un estudio histórico en particular, pero ciertamente podemos adelantar que el mortífero paso de la gripe española por el país estableció algunas lecciones para las generaciones posteriores.

Por un lado, podemos afirmar que las medidas generales de corte higiénico que se adoptaron con motivo de la pandemia, muchas de las cuales tenían su origen en el higienismo decimonónico, si bien no fueron suficientemente efectivas para hacer frente a la gripe, incrementaron entre la población la valoración por la educación higiénica, sobre todo en materia de hábitos de aseo y limpieza, hecho que nos permite subrayar una suerte de herencia pedagógica que dejó la influenza de 1918-1920. Por otro lado, se hizo patente que no sólo los médicos eran capaces de articular juicios en materia de salubridad, sino que los medios de comunicación podían canalizar puntos de vista para iluminar aquello que en la sociedad moderna se ha conocido como opinión pública, con propósitos que

${ }^{27}$ La Tribuna Médica, $1^{\circ}$ de noviembre de 1918; 216: 1262. abarcaron desde la denuncia de la inoperancia estatal, la difusión de normas sanitarias a fin de "acabar con mitos" vinculados a la salud, hasta la conducción de la expresión del malestar social de quienes vivieron en carne propia el azote de la gripe, sentimiento que se insertó en la faceta sanitaria de un fenómeno social y político de gran envergadura para el desarrollo de la vida nacional a comienzos del siglo XX, la cuestión social.

\section{Consideraciones finales}

El domingo 17 de mayo del año 2009, el ministro de Salud Álvaro Erazo comunicó oficialmente al país la aparición del primer caso de la pandemia de influenza H1N1 en Chile. En esa ocasión se informó que una mujer chilena que proveniente de República Dominicana había ingresado al Instituto Nacional de Enfermedades Respiratorias y Cirugía de Tórax-INERYCT (ex Hospital del Tórax) y se mantenía en estado de aislamiento. Para la mayoría de la población del país esa noticia generó expectación porque quizás fue la primera vez que conceptos poco familiares como influenza y pandemia se convirtieron en realidades palpables y alimentaron un panorama de incertidumbre colectiva insospechado hasta entonces. Sin embargo, para el cuerpo médico y los historiadores la presencia de la influenza no se constituyó como un hecho accidental.

Si miramos en perspectiva el episodio pandémico reciente de influenza porcina que se desarrolló a nivel global, nuestro país asumió en un contexto que difirió en un amplio sentido del escenario de 1918, pero que mantuvo algunas similitudes dignas de atención. Más allá de las ostensibles diferencias existentes en cuanto a la morbilidad y mortalidad ocasionadas por la influenza respecto a lo ocurrido en los años 1918-1920, el año 2009 nos enseña la consolidación de un aparato médico preventivo en el que ha sedimentado el conocimiento acerca de las experiencias conocidas en el mundo entero en torno a la influenza a lo largo del siglo XX y que en las últimas décadas fue coordinado por una institución supra-estatal, la Organización Mundial de la Salud, a través de varias iniciativas que contemplan un plan de acción conjunto internacional, que implica etapas de preparación y respuesta para enfrentar epidemias y pandemias de influenza, el cual constantemente es sometido a actualizaciones. ${ }^{28} \mathrm{~A}$ partir de este orden que integra al sistema médico nacional e internacional es posible afirmar que la historia de la influenza en Chile, que en 2009 registró un nuevo hito en su trayectoria, confirma aquello

${ }^{28}$ Un ejemplo elocuente de estas iniciativas globales de la OMS es el documento titulado Influenza pandemic plan. The roleof WHO and guidelines for national and regional planning, publicado en 1999. 
que anunciamos al comienzo del presente trabajo, esto es, el curso histórico que ha instaurado la unificación del mundo por las enfermedades. Mirado desde este ángulo, la respuesta médica a la contingencia pandémica redujo en un alto grado la confusión social.

No obstante, es menester señalar que pese a la existencia de una estrategia anti-influenza elaborada bajo cánones científicos altamente especializados en el combate contra las enfermedades infecciosas, las sensaciones de perplejidad una vez más se asentaron no en el campo médico, sino que en la población. No es pertinente asimilar estrechamente lo vivido a comienzos del siglo XX con lo acaecido hace pocos años con la influenza en Chile, pero sí corresponde dejar presente que algunas reacciones sociales que emergieron en 1918 tuvieron similitud con algunas aristas de nuestra cultura médica contemporánea. Un hecho que expresa fielmente lo que afirmamos es la distancia y desconfianza que despertó la persona que tosiera en un lugar público o que evidenciara síntomas propios de la gripe. También es digno de mención el papel que jugaron una vez más los medios de comunicación, a los que debemos añadir el potencial amplificador de internet, todo lo cual generó un caudal de informaciones entre la población que, por un lado, pudo contribuir a que las personas tomaran las precauciones correspondientes, y, por otra parte, aparecieran dudas en el terreno terapéutico, sobre todo por los cuestionamientos suscitados en torno a la actuación de un agente que en 1918 no estuvo presente: las empresas farmacéuticas. Este punto merece ser destacado porque revela que en el último evento de influenza que hemos conocido la "medicina popular", a diferencia de 1918, desempeñó un papel bastante secundario, y la medicación de fármacos, como el caso del tamiflu ${ }^{\circledR}$ (oseltamivir), fue la protagonista indiscutida, razón por la cual se ha hecho más sensible el tema del mercado de las medicinas y, especialmente, las tensiones existentes entre la salud pública o salud global y los intereses económicos de las Big Pharma que también gozan de una identidad globalizada ${ }^{29}$. Este tema

\footnotetext{
${ }^{29}$ Ver Informe de investigación sectorial sobre el sector farmacéutico emitido por la Unión Europea el 8 de julio de 2009
}

merece también una segunda mirada, esta vez desde una perspectiva histórica que nos remite a 1918 , puesto que si nos remitimos a las discusiones generadas en torno a medidas efectivas contra la gripe española, comprobamos que en ese escenario asomaron las acusaciones sobre los "intereses creados" de diversos agentes que para algunos constituían un impedimento para el combate de la pandemia. Tras 91 años de historia, la calidad de los protagonistas cambió, pero los puntos de tensión entre la medicina y su contexto social asomaron nítidamente en un escenario pandémico una vez más.

Por ahora, concluimos nuestro trabajo en el que hemos tratado de abordar en sus líneas generales un episodio particularmente importante para la historia médica de Chile en la década de 1910. Su valor investigativo se ha realzado no solamente en virtud del impacto de la pandemia de influenza H1N1 del 2009, sino porque además la óptica histórica indica una ruta para conocer el trasfondo globalizador que encierra el estudio de las enfermedades como factores fundamentales en el desarrollo de las sociedades desde hace siglos y la forma en que hemos valorado la salud en la historia profunda y reciente de nuestro país. Una visión que en el futuro se deberá tener en cuenta cuando, con toda seguridad, emerja otro episodio pandémico.

\section{Resumen}

En 1918 Chile conoció la mortífera presencia de la influenza española, la pandemia más importante del siglo XX. Para muchos historiadores, ese evento es un importante hito en el proceso histórico de la unificación del mundo a través de las enfermedades y en el cual nuestro país ha sido partícipe. En ese contexto, el presente artículo pretende examinar la forma en que la gripe irrumpió en la sociedad chilena y cómo esa coyuntura contribuyó a dar un nuevo impulso a la modernización de la salud pública chilena y a la instauración en la década de 1920 al modelo de la nueva medicina o medicina preventiva. 